\title{
In vivo targeted gene delivery to peripheral neurons mediated by neurotropic poly(ethylene imine)-based nanoparticles
}

This article was published in the following Dove Press journal:

International Journal of Nanomedicine

8 June 2016

Number of times this article has been viewed

\section{Cátia DF Lopes, ${ }^{1-3, *}$ Hugo Oliveira, ',* Inês Estevão,' Liliana Raquel Pires, ' Ana Paula Pêgo ${ }^{1,2,4,5}$ \\ 'INEB - Instituto de Engenharia Biomédica, Universidade do Porto (UPorto), Porto, Portugal; ${ }^{2} \mathrm{i} 3 \mathrm{~S}$ - Instituto de Investigação e Inovação em Saúde, NanoBiomaterials for Targeted Therapies Group, UPorto, Porto, Portugal; ${ }^{3}$ FMUP - Faculdade de Medicina da Universidade do Porto, Porto, Portugal; ${ }^{4}$ CBAS - Instituto de Ciências Biomédicas Abel Salazar, UPorto, Porto, Portugal; ${ }^{5}$ FEUP - Faculdade de Engenharia da Universidade do Porto, Porto, Portugal}

*These authors contributed equally to this work

\section{Video abstract}

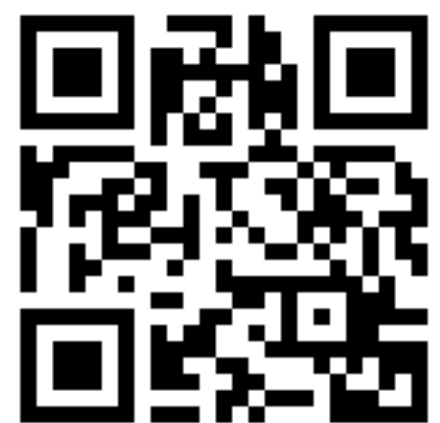

Point your SmartPhone at the code above. If you have a QR code reader the video abstract will appear. Or use: http://youtu.be/-93fEl05hwo

Correspondence: Ana Paula Pêgo i3S - Instituto de Investigação e Inovação em Saúde, Universidade do Porto, Rua Alfredo Allen, 208, 4200-I35 Porto, Portugal

Tel +35I 22408800

Email apego@ineb.up.pt
Abstract: A major challenge in neuronal gene therapy is to achieve safe, efficient, and minimally invasive transgene delivery to neurons. In this study, we report the use of a nonviral neurotropic poly(ethylene imine)-based nanoparticle that is capable of mediating neuron-specific transfection upon a subcutaneous injection. Nanoparticles were targeted to peripheral neurons by using the nontoxic carboxylic fragment of tetanus toxin (HC), which, besides being neurotropic, is capable of being retrogradely transported from neuron terminals to the cell bodies. Nontargeted particles and naked plasmid DNA were used as control. Five days after treatment by subcutaneous injection in the footpad of Wistar rats, it was observed that $56 \%$ and $64 \%$ of L4 and L5 dorsal root ganglia neurons, respectively, were expressing the reporter protein. The delivery mediated by HC-functionalized nanoparticles spatially limited the transgene expression, in comparison with the controls. Histological examination revealed no significant adverse effects in the use of the proposed delivery system. These findings demonstrate the feasibility and safety of the developed neurotropic nanoparticles for the minimally invasive delivery of genes to the peripheral nervous system, opening new avenues for the application of gene therapy strategies in the treatment of peripheral neuropathies.

Keywords: gene therapy, nonviral vector, neuron-targeted, peripheral neurons

\section{Introduction}

Peripheral neuropathy is a clinical condition highly prevalent worldwide that still awaits efficient treatment options. Although peripheral neurons have intrinsic regenerative capacities, the provision of specific trophic factors to the injured neurons can result in a significant improvement in their survival and regeneration efficiency. Nonetheless, a reduced plasma half-life and adverse effects in nontargeted tissues as a consequence of systemic administration have limited their clinical application. ${ }^{1}$ An alternative approach to achieve a controlled and targeted delivery of trophic factors in the nervous system is the use of gene-based therapies, in which a transgene encoding for a therapeutic protein is introduced into the target cells. However, the development of safe and efficient vectors for in vivo gene transfer remains a main challenge in order to attain the promise of gene therapy.

Gene transfer to the peripheral nervous system has been previously explored, mainly through the use of viral vectors, since some have natural neurotropism and are associated with high transduction efficiencies. ${ }^{2}$ However, in spite of important advances toward the increased safety of viral vehicles, they still present risks regarding toxicity and immunogenicity. ${ }^{3}$ In turn, nonviral gene delivery vectors have become attractive 
alternatives to their viral counterparts, offering better safety profiles, although the majority continues to show low gene transfer efficiency. ${ }^{4}$ Together with safety and efficiency issues, crucial requirements for in vivo gene therapy are the specific targeting of the desired cell population as a way to avoid off-target delivery and increase the transgene expression in the target tissue, assured by a minimally invasive administration route. Despite the wide number of nonviral gene delivery vectors proposed in the past, to the best of our knowledge, none has been developed to actively target peripheral neurons following a minimally invasive peripheral route of administration. Thus, such development is of significant interest not only for safety issues, but also to aid in the design of more clinically relevant therapeutic applications to treat neuropathic conditions. To this end, we have previously described the development of a nonviral gene delivery vector based on poly(ethylene imine) (PEI) targeted to peripheral neurons by its functionalization with a pegylated nontoxic carboxylic fragment of tetanus toxin $(\mathrm{HC}) .^{5}$ The $\mathrm{HC}$ fragment is neurotropic and can undergo active retrograde transport after peripheral administration. ${ }^{6,7}$ Indeed, its potential as a therapeutic carrier has already been explored as a coupling agent to mediate the transport of proteins or viral vectors to neurons. ${ }^{8-10}$ When functionalized with the pegylated $\mathrm{HC}$ fragment, the developed thiolated PEI-based nanoparticles (PEISH-HC) showed the ability to transfect primary cultures of dissociated dorsal root ganglia (DRG) neurons in a specific fashion. ${ }^{5}$ Here, we aimed to evaluate the in vivo performance of these targeted nanoparticles, assessing their capacity to retrogradely access and transfect lumbar DRG neurons after a peripheral and minimally invasive administration in the animal's footpad. We hypothesize that after footpad injection, the nanoparticles contact the sensorial terminals, are internalized in a cell-specific fashion, are transported toward the DRGs that innervate the injection site, and lead to the local expression of the transgene.

\section{Materials and methods Materials}

Branched PEI(25 kDa, Sigma-Aldrich Co., StLouis, MO, USA) was thiolated with 2-iminothiolane (Sigma-Aldrich Co.) and purified as previously described. ${ }^{5}$ The thiolated PEI (PEISH) was dissolved at $1 \mathrm{mg} / \mathrm{mL}$ in a $5 \%(\mathrm{w} / \mathrm{v})$ glucose solution (pH 7.4) and stored at $-80^{\circ} \mathrm{C}$ until further use. The plasmid DNA (pDNA) encoding for GFP and $\beta$-galactosidase ( $p$ VIVO1-GFP-LacZ, 8.4 kb, Invivogen, San Diego, CA, USA) was used throughout the study. Plasmid was produced in a DH5 $\alpha$ competent Escherichia coli strain transformed with the respective plasmid. Subsequently, DNA purification was performed using an endotoxin-free Maxiprep kit following the manufacturer's instructions (GenElute, Sigma-Aldrich Co.). The $\mathrm{HC}$ fragment was produced recombinantly using the BL21 E. coli strain. The plasmid encoding for the HC fragment was a kind offer from Prof Neil Fairweather (King's College, UK). The HC production in the BL21 E. coli strain and purification was performed as previously described. ${ }^{11}$ The obtained HC fragment was additionally covalently linked to a bi-functional poly(ethylene glycol) (PEG) spacer. Briefly, a bi-functional 5 kDa PEG (JenKem Technology USA, Plano, TX, USA) bearing an N-hydroxysuccinimide and a maleimide end group was used as indicated by the manufacturer, at a $2.5 \mathrm{PEG} / \mathrm{HC}$ protein molar ratio. ${ }^{5}$

\section{Nanoparticles' preparation}

Nanoparticles were prepared as previously described with an $\mathrm{N} / \mathrm{P}$ molar ratio of 3 (N/P - moles of primary amine groups [N] of PEI to moles of DNA phosphate groups [P]) and a final concentration of $7.5 \mu \mathrm{g}$ pegylated $\mathrm{HC}$ per $2 \mu \mathrm{g}$ of pDNA. ${ }^{5}$ Briefly, the nanoparticle core was formed by mixing, while vortexing, equal volumes of pDNA and PEISH solution in 5\% (w/v) glucose in water ( $\mathrm{pH}$ 7.4). Complexes were left to form for 15 minutes at room temperature. Subsequently, pegylated $\mathrm{HC}$ fragment (reactive to thiol moieties by a maleimide terminal group in the $5 \mathrm{kDa} P E G$ ) was added to the complex mixture at a final concentration of $7.5 \mu \mathrm{g}$ per $2 \mu \mathrm{g}$ of pDNA and ternary complexes were left to form for 24 hours at room temperature. Prior to use, the nanoparticle dispersion was concentrated to a final pDNA concentration of $500 \mu \mathrm{g} / \mathrm{mL}$ in $5 \%(\mathrm{w} / \mathrm{v})$ glucose aqueous solution (pH 7.4) using a $30 \mathrm{kDa}$ cutoff filter (Amicon Ultra, EMD Millipore, Billerica, MA, USA).

\section{Nanoparticles' physicochemical characterization}

PEISH-based nanoparticles with and without HC functionalization were characterized in terms of size, polydispersity index (Pdi), and zeta potential using a Zetasizer Nano Zs (Malvern Instruments, Malvern, UK). The Smoluchowski model was applied for zeta potential determination and cumulant analysis was used for mean particle size determination. Ten $\mu \mathrm{g}$ of pDNA was used to prepare the tested formulations. All measurements were performed in triplicate at $25^{\circ} \mathrm{C}$. The morphology of the PEISH-based nanoparticles was evaluated by transmission electron microscopy (TEM). Briefly, $10 \mu \mathrm{L}$ of the nanoparticle suspension was placed on a grid, treated with sodium phosphotungstate, and observed in a TEM Zeiss 902 A. To assess the distribution of the 
pegylated HC fragment on the surface of the nanoparticle core, a parallel experiment was performed in which $\mathrm{HC}$ fragment was coupled to Qdot ${ }^{\circledR} 800$ ITK $^{\text {TM }}$ carboxyl quantum dots (Molecular Probes, Eugene, OR, USA) before its complexation with the thiolated nanoparticles. The resulting nanoparticles were adsorbed on a grid and imaged by TEM, without any further treatment.

\section{Animals and in vivo nanoparticles' administration}

All animal experiments were carried out with the permission of the local animal ethics committee Instituto de Biologia Molecular e Celular (IBMC)-Instituto de Engenharia Biomédica (INEB), Associated Laboratory, Porto, Portugal) in accordance with the EU Directive (2010/63/EU) and Portuguese law (DL 113/2013). The experimental protocol was approved by the ethics committee of the Portuguese official authority on animal welfare and experimentation (DireçãoGeral de Alimentação e Veterinária). A total of 34 male 4-month old Wistar rats, with an average weight of 350-400 $\mathrm{g}$ were used in this study. Animals were randomly divided into three groups as follows: A) pDNA group (subcutaneous injection of pDNA in $5 \%(\mathrm{w} / \mathrm{v})$ glucose aqueous solution ( $\mathrm{pH} 7.4), \mathrm{n}=6$ ); B) PEISH group (subcutaneous injection of PEISH nanoparticles in 5\% (w/v) glucose aqueous solution (pH 7.4), n=14); and C) PEISH-HC group (subcutaneous injection of HC-functionalized PEISH nanoparticles in 5\% (w/v) glucose aqueous solution ( $\mathrm{pH} 7.4$ ), n=14). For nanoparticles' administration, animals were anesthetized by the inhalation of isoflurane and the site of administration was disinfected with ethanol. Nanoparticle or pDNA dispersions were administrated unilaterally in left footpad $(150 \mu \mathrm{L}$ of dispersion corresponding to $75 \mu \mathrm{g}$ of pDNA) using a 25-gauge needle (Hamilton, Bonaduz, Switzerland). At 3 and 5 days postinjection, animals were sacrificed by a lethal intraperitoneal injection of $20 \%(\mathrm{v} / \mathrm{v})$ sodium pentobarbital. In group A, and per time point, the tissue samples of two animals were processed for gene expression analysis by real-time reverse transcriptase-polymerase chain reaction (RT-PCR) and the tissue sample of one animal was processed for GFP expression detected by immunohistochemistry. In groups $\mathrm{B}$ and $\mathrm{C}$, five and two animals were used, respectively. Tissues were collected and snap-frozen or fixed in $4 \%(\mathrm{v} / \mathrm{v})$ buffered formalin for total RNA extraction or histological analysis, respectively. The following tissues were collected: posterior footpads, lymph nodes that drain the back limb region (ie, popliteal and inguinal), whole blood, sciatic nerves, L1-L4 ventral roots (VR), L4-L5 DRGs, heart, liver, spleen, kidneys, and lungs.

\section{RNA extraction and real-time RT-PCR}

Total RNA was extracted from designated tissues using the PureLink RNA Mini kit (Thermo Fisher Scientific, Waltham, MA, USA) according to the manufacturer's instructions. Reverse transcription was obtained from $500 \mathrm{ng}$ of total RNA employing the Superscript First-Strand Synthesis System (Thermo Fisher Scientific). For real-time quantification of GFP mRNA levels, the synthesized complementary DNAs were amplified in duplicate in an iCycler iQ5 (Bio-Rad Laboratories Inc., Hercules, CA, USA) using iQ SYBR Green Supermix (Bio-Rad Laboratories Inc.). The following gene sequences were designed and synthesized: GFP sense primer: 5'-CTGTCCAACTGGCAGACCATTACC-3', antisense primer: 5'-TTCCTGCTGCTGTCACAAACTCC-3'; glyceraldehyde 3-phosphate dehydrogenase (GAPDH) sense primer: 5'-TTCACACCCATCACAAACAT-3', antisense primer: 5'-GCCATCAACGACCCCTTCAT-3'. At the end of the PCR cycling, correspondent melting curves were performed in order to ascertain the amplification of a single product and the absence of primer dimer formation. $G A P D H$ gene was used as an internal control to normalize the variability in expression levels. The relative GFP mRNA expression levels in treatment groups were calculated relative to the control naked pDNA group using the 2- $\Delta \Delta \mathrm{CT}$ method described by Livak and Schmittgen, normalized with the average expression of GAPDH. ${ }^{12}$

\section{Histological analysis}

Formalin-fixed tissues were processed and embedded in paraffin to prepare $4 \mu \mathrm{m}$ paraffin sections. Dewaxed tissue sections were prepared for hematoxylin and eosin staining (ie, footpads) or for immunohistochemistry to detect the expression of GFP protein in the DRGs. The hematoxylin and eosin-stained footpad sections were used to qualitatively analyze the inflammatory response in the injection site as a result of the nanoparticle administration. The immunodetection of GFP protein in DRGs was used to calculate the in vivo transfection efficiency of DRGs mediated by PEI-based nanoparticles. Polyclonal rabbit anti-GFP (1:500, A11122, Thermo Fisher Scientific) and secondary antibody peroxidase polymer-labeled anti-rabbit (Dako Denmark A/S, Glostrup, Denmark) were used. The antibody reaction was revealed with diaminobenzidine (Vector Laboratories, Burlingame, CA, USA) and tissue sections were counterstained with hematoxylin. To determine the transfection efficiency of PEISH-HC nanoparticles, the number of GFP positive L4 and L5 DRG neurons were counted in each $150 \mu \mathrm{m}$ section for each sample. This corresponds to 5-6 sections and, on average, 1,000 neurons counted per DRG. 


\section{Statistical analysis}

Statistical analysis was performed using GraphPad Prism version 5.0 for Windows (GraphPad Software, Inc., La Jolla, CA, USA). Results are presented as mean \pm standard deviation. D'Agostino and Pearson omnibus normality tests were used to test whether data obeyed a Gaussian distribution. The non-parametric Mann-Whitney $U$-test was performed to compare treatment groups. A result with $P<0.05$ was considered statistically significant.

\section{Results and discussion}

The strategy followed for the development of neurotropic PEISH-based nanoparticles has been previously described by us. ${ }^{5}$ As a first step, the PEISH is complexed with a pDNA suspension resulting in a naked complex. In the second step, the thiol-decorated complex is functionalized with the $\mathrm{HC}$ fragment via a $5 \mathrm{kDa}$ bi-functional PEG linker, which is thiol-reactive, resulting in the formation of a targeted complex (Figure 1A). Here, we explored the in vivo performance of the proposed PEISH neurotropic nanoparticles, prepared at an N/P ratio of 3. This formulation was chosen as it has been previously shown, based on molecular recognition force spectroscopy studies, ${ }^{13}$ to possess an optimal targeting profile toward neuronal cells in vitro, as well as mediating targeted sensory neuron cell transfection in dissociated DRG primary cultures. ${ }^{5}$ The tested nanoparticle formulations - the neurotropic nanoparticles based on PEISH-HC and the nontargeted PEISH based nanoparticles - were fully characterized in terms of size, Pdi, zeta potential, and morphology. In Figure 1B the presented table summarizes the physicochemical characterization of both formulations. The mean size diameter values obtained were $63.0 \pm 5.5 \mathrm{~nm}$ for naked nanoparticles and $63.0 \pm 6.0 \mathrm{~nm}$ for PEISH-HC nanoparticles, with the respective Pdi values $0.35 \pm 0.03$ and $0.32 \pm 0.03$. The mean diameter of
A

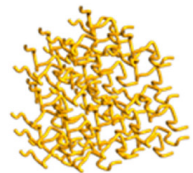

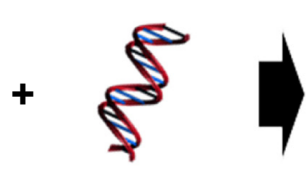

Plasmid DNA

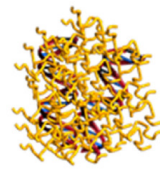

PEISH complex

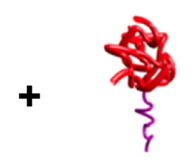

HC fragment

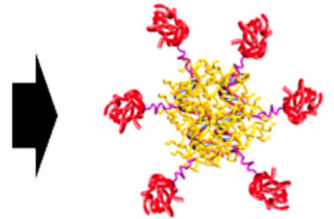

PEISH-HC complex

B

\begin{tabular}{llll}
\hline Formulation & Size $(\mathbf{n m})$ & Pdi & Zeta potential $(\mathbf{m V})$ \\
\hline PEISH & $63.0 \pm 5.5$ & $0.35 \pm 0.03$ & $24.5 \pm 4.0$ \\
\hline PEISH-HC & $63.0 \pm 6.0$ & $0.32 \pm 0.03$ & $27.9 \pm 5.0$ \\
\hline
\end{tabular}

C
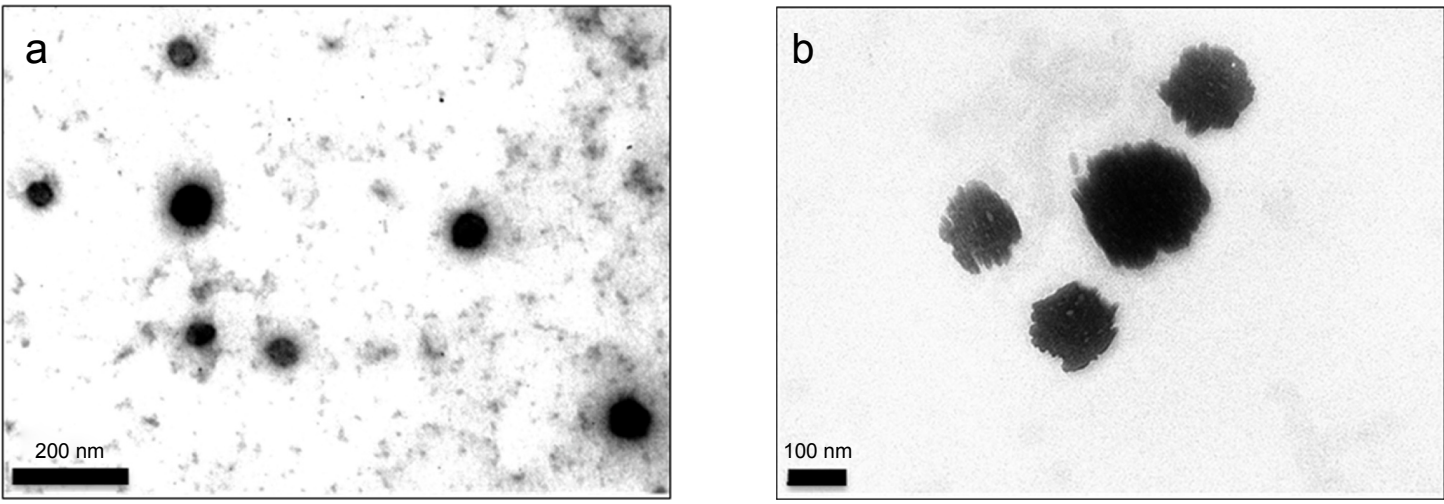

Figure I PEISH-based nanoparticle characterization.

Notes: (A) Scheme of nanoparticle synthesis. Modified from Oliveira H, Fernandez R, Pires LR, et al; Targeted gene delivery into peripheral sensorial neurons mediated by self-assembled vectors composed of poly(ethylene imine) and tetanus toxin fragment c; J Control Release; I43; 350-358; Elsevier; Copyright (C 20I0.5 (B) Physicochemical characterization of PEISH-based nanoparticles at N/P ratio of 3 ( $n=3$, mean $\pm \mathrm{SD}$ ). (C) TEM photomicrographs of sodium phosphotungstate counterstained PEISH-HC nanoparticles (a) and HC-quantum dots functionalized nanoparticles (b).

Abbreviations: PEISH, thiolated poly(ethylene imine); Pdi, polydispersity index; N/P, moles of primary amine groups (N) of poly(ethylene imine) to moles of DNA phosphate groups (P); SD, standard deviation; TEM, transmission electron microscopy; HC, carboxylic fragment of tetanus toxin. 
PEISH-HC nanoparticles is not significantly different than the naked nanoparticles showing that $\mathrm{HC}$-functionalization does not influence the size of the nanoparticles. Zeta potential values obtained for naked and PEISH-HC nanoparticles were $24.5 \pm 4.0$ and $27.9 \pm 5.0 \mathrm{mV}$ respectively, indicating a cationic surface charge of nanoparticles with a good colloidal stability. The morphology of both nanoparticle formulations was assessed by TEM. In Figure 1C(a) a photomicrograph depicts PEISH-HC nanoparticles, being a representative image of the observed nanoparticle populations. These exhibited a spherical shape with no signs of aggregation. In Figure 1C(b), one can observe that the $\mathrm{HC}$ moieties grafted to the nanoparticles core are disposed at the surface of the nanoparticles, supporting the previously gathered evidences that the presence of the $\mathrm{HC}$ fragment at the nanoparticle surface confers the targeting features to these nanoparticles.

A single dose of naked pDNA, PEISH, or PEISH-HC nanoparticle dispersion in 5\% (w/v) glucose aqueous solution (pH 7.4), carrying $75 \mu \mathrm{g}$ of pVIVO1-GFP-LacZ pDNA, was injected in the left footpad of adult Wistar rats. Previous studies regarding the peripheral administration of cationized gelatin-based nanoparticles reported transgene expression from 60 hours to 6 days post-posterior rat footpad injection. ${ }^{14}$ In order to assess the ability of developed nanoparticles to efficiently access DRG neuron cell bodies after peripheral administration in the footpad, we evaluated the GFP transgene expression in the sciatic nerves, VR, and DRGs at 3 and 5 days post-administration.

In the case of animals treated with pDNA alone, the GFP expression was not detected in the sciatic nerve, VR, and DRG either at 3 or 5 days post-administration (data not shown).

With regard to PEISH nanoparticles, at 3 days postadministration, a 1 and 4.3 average fold increase in $G F P$ expression levels (relative to the expression levels in naked pDNA control group) could be detected in the sciatic nerves and DRGs, respectively (Figure 2A, C). Conversely, at day 5, no GFP expression was observed in the analyzed tissues (Figure 2B, C). Animals treated with the PEISH-HC nanoparticles showed a 9 and 2.8 average fold increase in GFP expression at the VR and DRGs at day 3, respectively (Figure 2A, C). Over the course of time, the GFP expression levels in DRGs further increased to four-fold (Figure 2B, C). These results proved that the transgene could be detected in DRGs as early as 3 days after footpad injection, and suggest that HC-grafted nanoparticles were retrogradely transported within the rate of fast active retrograde axonal transport (100-250 mm per day), ${ }^{15}$ as passive diffusion could not account for the covered distance. Indeed, it has been shown that the nerve length from the toe to the dorsal root entry was in the range of $17 \mathrm{~cm}$ in an adult rat, ${ }^{16}$ what implies an active retrograde transport of the nanoparticles in order to reach the DRG in the observed period of time. At day 5, the transgene expression levels in DRG increased in relation to day 3 and, additionally, immunohistochemistry analysis at this time point showed that the transgene reporter protein could be detected (Figure 2D(a) and (b)).

Based on these results, we propose that the HC-functionalized nanoparticles were internalized at neuron terminals and followed retrograde fast axonal transport to the sensorial neuron cell bodies where they accumulated and led to transgene expression. Previous studies reported the ability of naked PEI-based nanoparticles to be retrogradely transported after subcutaneous administration in the footpad. ${ }^{14}$ Our results are in accordance with these data, showing that naked PEISH-based nanoparticles were also able to deliver the GFP gene into DRGs, but they were not as efficient as their targeted counterparts and did not persist over time or resulted in reporter protein translation at detectable levels (Figure 2D(c) and (d)). ${ }^{14,17,18}$

One of the major limitations identified in nonviral gene delivery vectors is their inefficient transfection capacity. Here, we have shown that the developed neuron-targeted PEISH-HC nanoparticles were able to mediate the transfection and protein expression of $56 \%$ and $64 \%$ of L4 and L5 DRG neurons at 5 days post-administration (Figure 2E). The L4 and L5 DRG neurons are the ones which contribute more to the sciatic nerve that innervates the footpad. ${ }^{19}$ A previous study regarding the subcutaneous footpad administration of recombinant adeno-associated serotype 6 viruses reported a transduction efficiency of L4 DRG neurons at less than $10 \%$, at 3 weeks post-administration. ${ }^{20}$ Also, the subcutaneous injection of cationized gelatin-based nanoparticles resulted in a transfection efficiency of approximately $10 \%$ of L4 and L5 DRG neurons. ${ }^{14}$ These results highlight the improved transfection efficiency achieved in this work by means of active targeting toward peripheral neurons.

As important as the ability to reach the target tissues, is the capacity to reduce off-target distribution. In this sense we evaluated the transgene biodistribution profile, mediated by naked pDNA, PEISH, or PEISH-HC nanoparticles, upon subcutaneous administration, by assessing GFP mRNA expression in the following non-neuronal tissues: injected paws, left popliteal and inguinal lymph nodes (which drain the injected paws), whole blood, heart, liver, spleen, kidneys, and lungs. At 3 days post-injection, animals administered with pDNA alone revealed GFP gene expression solely in the injected paws (Figure 3A). However, at day 5, the transgene expression was detected in the majority of the tissues evaluated (Figure 3B). In PEISH-treated animals, the GFP transgene 
A

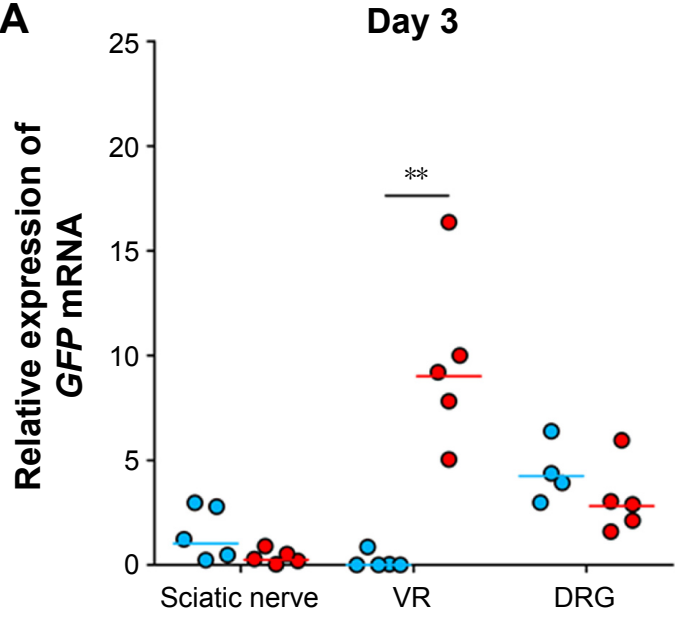

B

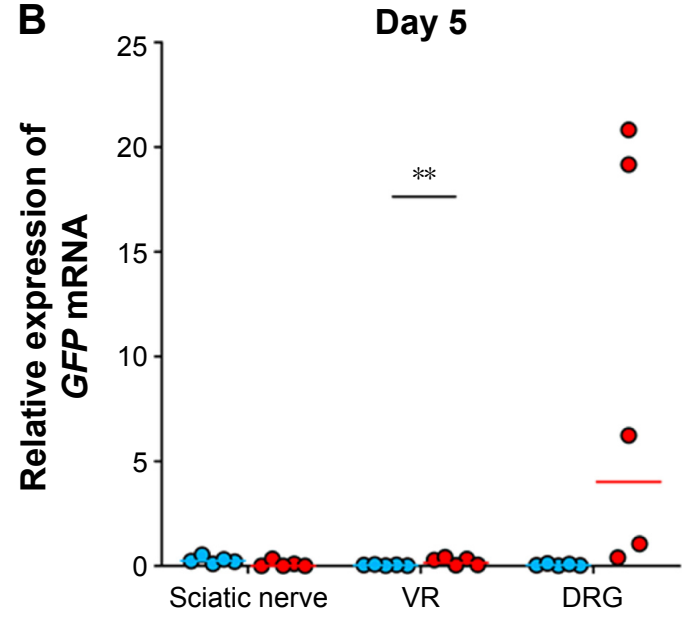

O PEISH O PEISH-HC

\begin{tabular}{|c|c|c|c|c|c|c|c|c|c|c|c|c|}
\hline \multirow[t]{3}{*}{ C } & \multicolumn{6}{|l|}{ PEISH } & \multicolumn{6}{|l|}{ PEISH-HC } \\
\hline & \multicolumn{3}{|l|}{3 days } & \multicolumn{3}{|l|}{5 days } & \multicolumn{3}{|l|}{3 days } & \multicolumn{3}{|l|}{5 days } \\
\hline & $\begin{array}{l}\text { Average } \\
\text { fold change }\end{array}$ & SD & $95 \% \mathrm{Cl}$ & $\begin{array}{l}\text { Average } \\
\text { fold change }\end{array}$ & $\mathrm{SD}$ & $95 \% \mathrm{Cl}$ & $\begin{array}{l}\text { Average } \\
\text { fold change }\end{array}$ & SD & $95 \% \mathrm{Cl}$ & $\begin{array}{l}\text { Average } \\
\text { fold change }\end{array}$ & SD & $95 \% \mathrm{Cl}$ \\
\hline Sciatic nerves & 1.0 & 0.5 & 0.4 & 0.2 & 0.3 & 0.2 & 0.2 & 0.6 & 0.5 & 0.0 & 1.6 & 1.4 \\
\hline Ventral roots & 0.0 & 1.3 & 1.2 & 0.0 & 0.3 & 0.3 & 9.0 & 0.2 & 0.2 & 0.1 & 0.5 & 0.4 \\
\hline DRGs & 4.3 & 0.1 & 0.1 & 0.0 & 0.4 & 0.3 & 2.8 & 0.2 & 0.2 & 4.0 & 0.8 & 0.7 \\
\hline
\end{tabular}

D
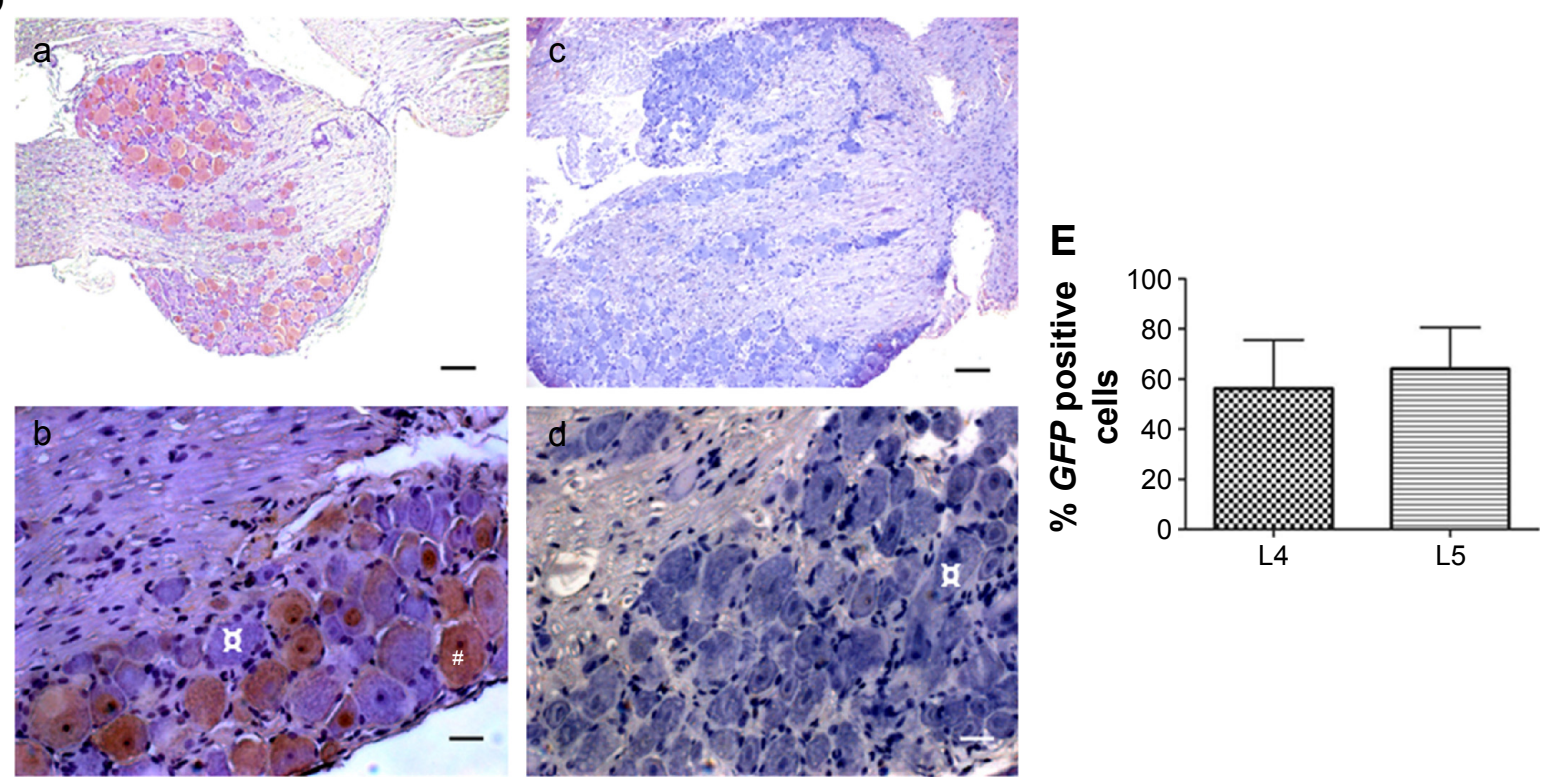

Figure 2 Reporter gene expression in neuronal tissues.

Notes: Relative GFP gene expression in neuronal tissues was evaluated at 3 (A) and 5 days (B) post-administration of PEl-based nanoparticles in the left footpad. (C) Statistical data characterization $(n=5)$. (D) GFP protein expression in lumbar DRGs from animals treated with PEISH (c, d) or PEISH-HC nanoparticles (a, b) at 5 days postadministration. (E) Transfection efficiency of lumbar L4 and L5 DRG neurons mediated by PEISH-HC nanoparticles at day 5 post-administration. Mean \pm SD. (A and B) The GFP mRNA expression levels were normalized by GAPDH mRNA expression levels in each tissue sample and represented as relative to the GFP expression in naked pDNA control group. We considered the sciatic nerves, VR, and L4-L5 DRG as neuronal tissue. Each dot represents one animal. **Denotes $P<0.01$; lines represent the geometric mean. (D) \#Indicates a GFP positive cell; aindicates a GFP negative cell. Scale bars $=100 \mu \mathrm{m}$ (a, c) or $25 \mu \mathrm{m}$ (b, d).

Abbreviations: PEI, poly(ethylene imine); PEISH, thiolated poly(ethylene imine); GAPDH, glyceraldehyde 3-phosphate dehydrogenase; pDNA, plasmid DNA; VR, ventral roots; DRG, dorsal root ganglia; SD, standard deviation; $\mathrm{Cl}$, confidence interval; $\mathrm{HC}$, carboxylic fragment of tetanus toxin. 
could be detected in the injected paws, lymph nodes, heart, and liver at 3 and 5 days post-administration, and additionally in blood and spleen at 3 days post-administration (Figure 3). In contrast with these observations, animals treated with HC-functionalized PEISH nanoparticles revealed a restricted expression of GFP mRNA in non-neuronal tissues. As illustrated in Figure 3, the transgene expression was only detected in the injected paws and lymph nodes at both time points, and in the blood at 5 days post-administration. Moreover, the GFP gene expression levels in paws and lymph nodes were considerably lower in animals treated with PEISH-HC nanoparticles at both time points (Figure 3C, D). These results further support that $\mathrm{HC}$-functionalized nanoparticles are able to spatially limit the transgene expression, in comparison with the nontargeted nanoparticles and naked pDNA, significantly reducing the possibility of unwanted off-target effects.
To further assess the impact of the local administration of the developed vectors, we evaluated the inflammatory response in the footpad at 3 and 5 days post-administration. In the first hours post-administration, independently of the tested formulation, animal footpads presented a moderate swelling indicative of a mild inflammatory reaction as a consequence of the injection, but 24 hours later the rat footpads regained their normal appearance and the animals showed normal use of the limb. Histologic analysis of the footpad at 3 and 5 days post-injection showed infiltration of inflammatory cells in the injection site (Figure 4). However, no relevant differences were observed between treatment groups, and the general behavior of animals under the tested conditions indicated that the developed systems do not induce a harmful effect, with neither footpad sensitization nor significant animal weight variation (data not shown) being observed, suggesting their safety.

A

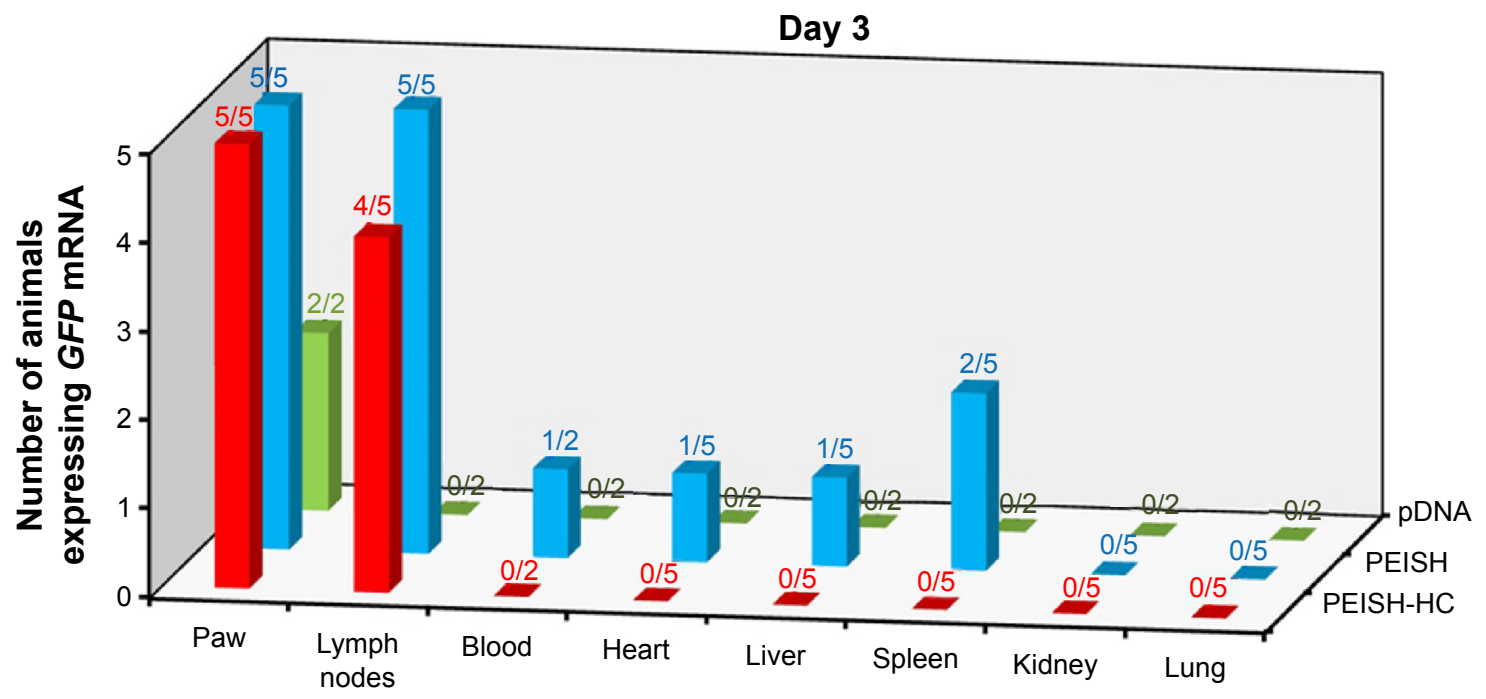

B

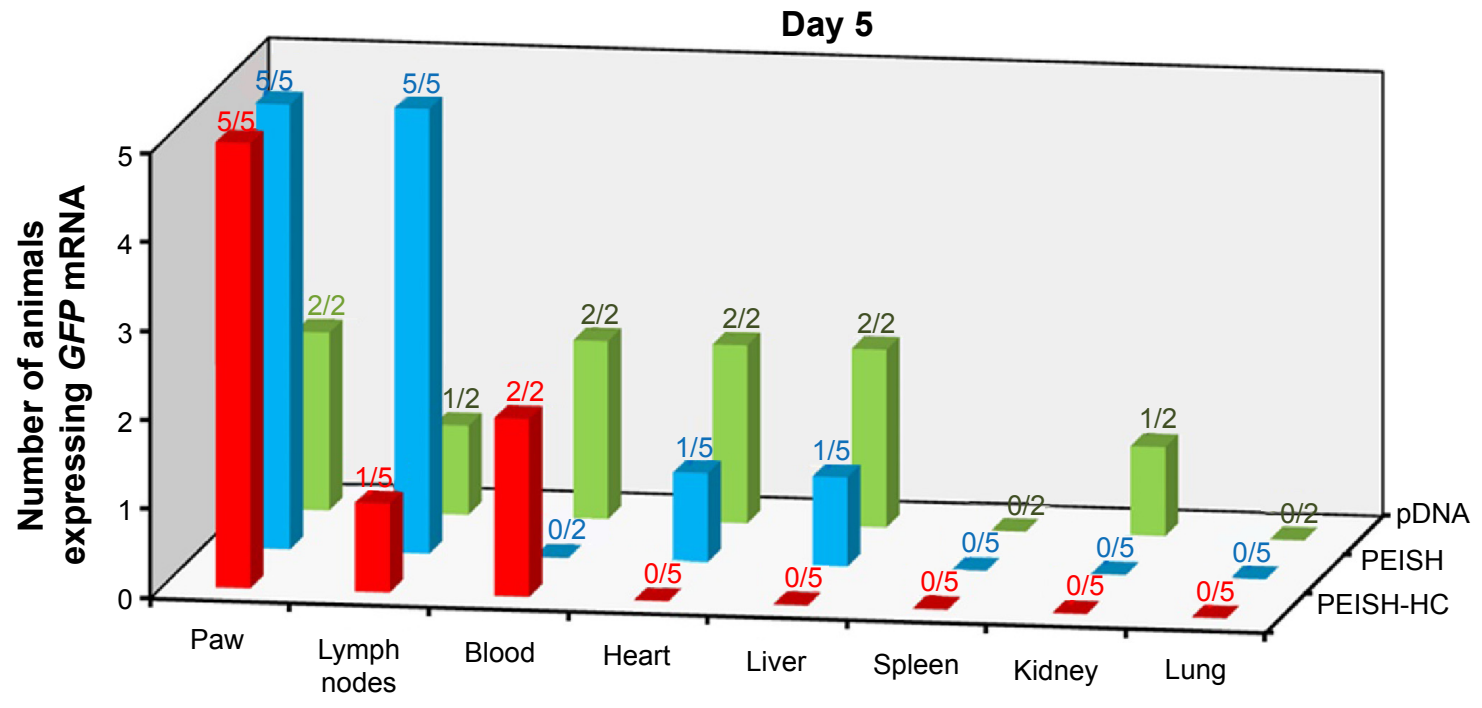

Figure 3 (Continued) 


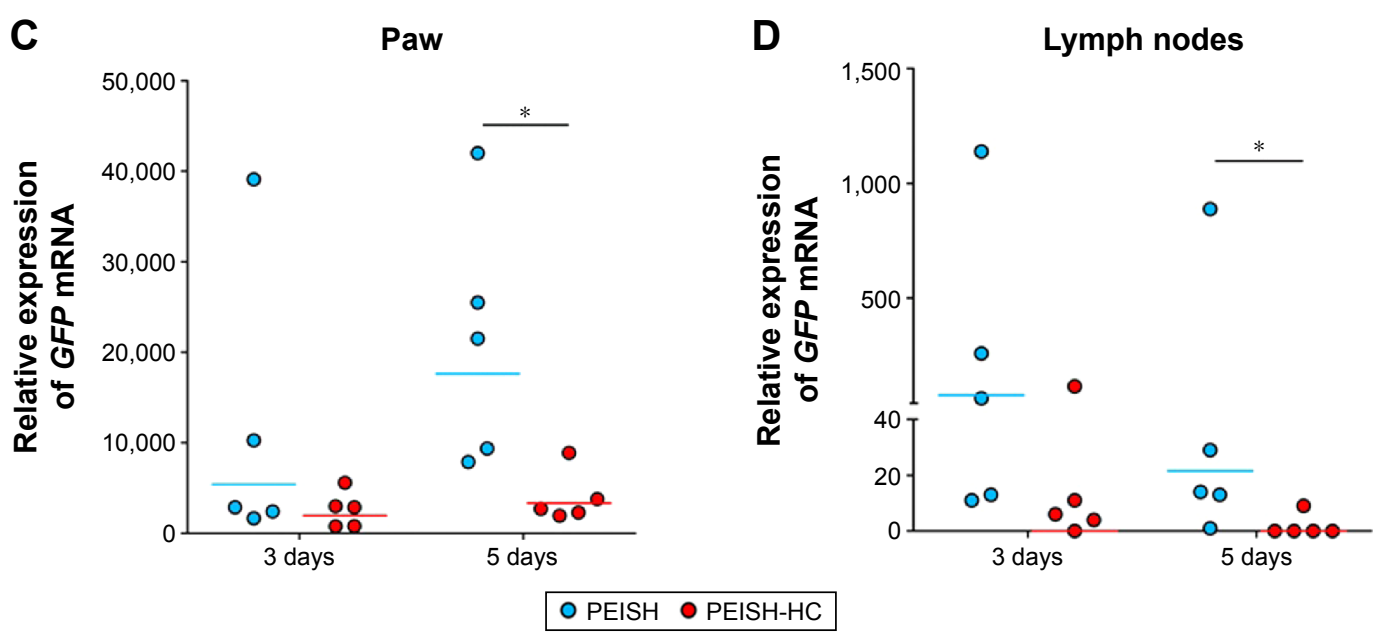

Figure 3 Reporter gene expression in non-neuronal tissues.

Notes: Firstly, GFP mRNA expression profile was qualitatively evaluated in non-neuronal tissues at 3 (A) and 5 (B) days post-administration. Relative GFP gene expression in paw (C) and lymph nodes (D) at 3 and 5 days post-administration of PEl-based nanoparticles in the left footpad. (A and $\mathbf{B})$ For each tissue, over the columns, the number of animals expressing GFP mRNA in relation to the total number of animals evaluated is indicated (ie, I/5 indicates one animal expressing GFP mRNA in a total of five animals analyzed at the same time point). ( $C$ and $\mathbf{D}) *$ Denotes $P<0.05$; lines represent the geometric mean.

Abbreviations: pDNA, plasmid DNA; PEI, poly(ethylene imine); PEISH, thiolated poly(ethylene imine); HC, carboxylic fragment of tetanus toxin.

\section{Conclusion}

This study demonstrates the efficient and targeted delivery of a reporter gene mediated by HC-modified PEISH-based nanoparticles to DRG sensorial neurons through a peripheral administration in the footpad. Likewise, these neurotropic nanoparticles can be used to carry plasmids encoding for any relevant therapeutic gene in the nervous system, such as genes encoding for the neurotrophins $\mathrm{NGF}^{21}$ and $\mathrm{BDNF},{ }^{5}$ or pain-relief associated genes like $P E N K{ }^{22}$ Such a targeted, versatile, and minimally invasive approach may prove to be
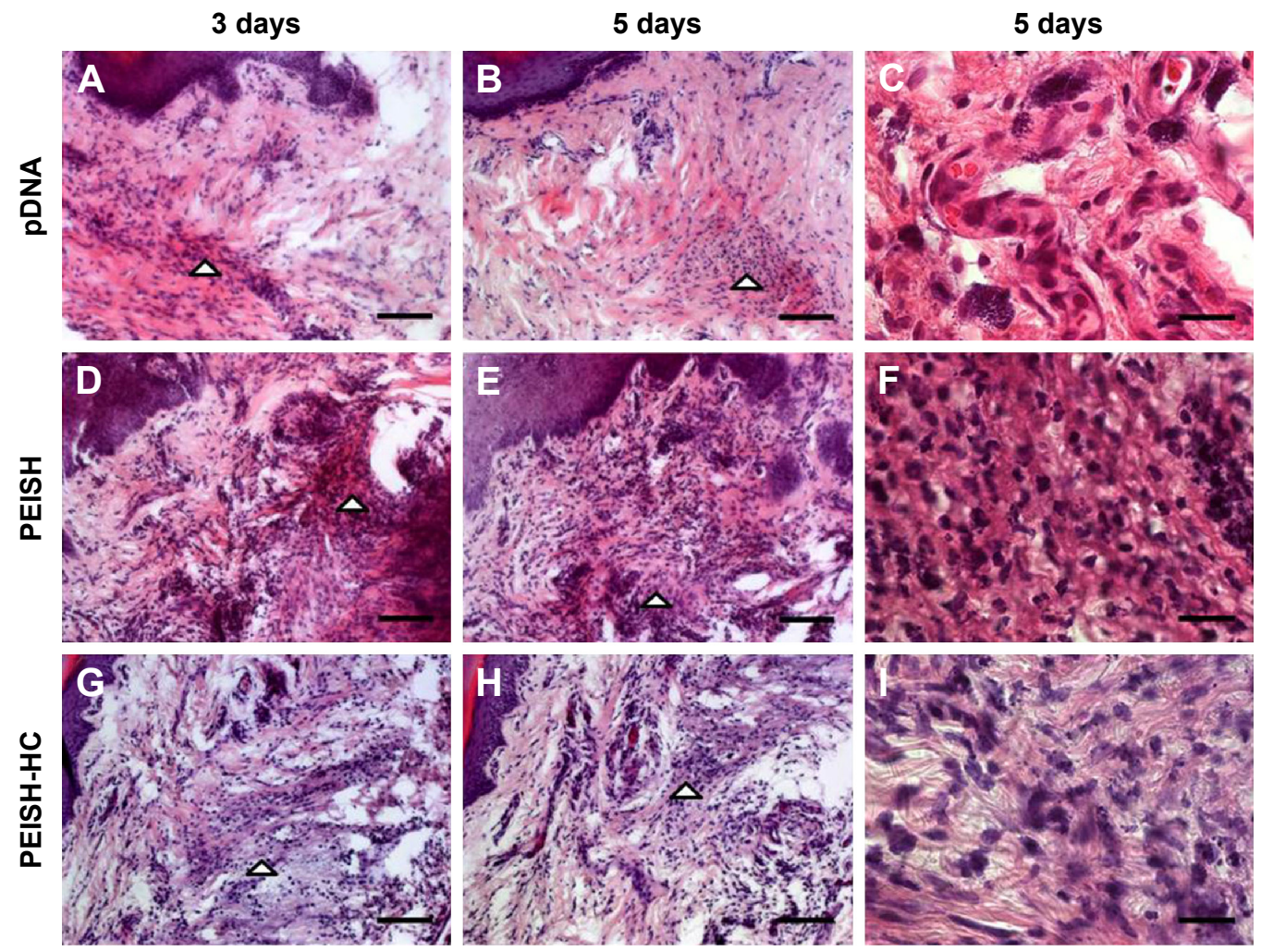

Figure 4 Inflammatory response in the injection site.

Notes: Representative images of footpad subcutaneous tissue at 3 days $(\mathbf{A}, \mathbf{D}$, and $\mathbf{G}$, scale bars $=100 \mu \mathrm{m})$ and 5 days $(\mathbf{B}, \mathbf{E}$, and $\mathbf{H}$, scale bars $=100 \mu \mathrm{m}$; and $\mathbf{C}$, $\mathbf{F}$, and $\mathbf{I}$, scale bars $=20 \mu \mathrm{m}$ ) post-administration of naked pDNA (A-C), PEISH nanoparticles (D-F) or PEISH-HC nanoparticles (G-I). Arrowheads indicate the presence of infiltrating inflammatory cells.

Abbreviations: pDNA, plasmid DNA; PEISH, thiolated poly(ethylene imine); HC, carboxylic fragment of tetanus toxin. 
useful for exploring new therapeutic strategies valuable for the treatment of sensory neuropathy, by stimulating sensory axon regeneration and/or preventing neuronal degeneration in the DRG, as well as for the relief of pain states resulting from various clinical conditions.

\section{Acknowledgments}

We acknowledge Dr Teresa Summavielle (i3S - Instituto de Investigação e Inovação em Saúde/IBMC - Instituto de Biologia Molecular e Celular) and Dr Meriem Lamghari (i3S Instituto de Investigação e Inovação em Saúde/INEB - Instituto de Engenharia Biomédica,) for their precious help regarding the in vivo study design and optimization; Dr Fani Neto, Dr António Avelino, and Dr Sara Adães (FMUP - Faculdade de Medicina da Universidade do Porto) for their help in tissue isolation; and Dr Rui Fernandes for the help with TEM analysis. This work was financed by FEDER - Fundo Europeu de Desenvolvimento Regional funds through the COMPETE 2020 - Operational Programme for Competitiveness and Internationalisation (POCI), Portugal 2020, and by Portuguese funds through Fundação para a Ciência e a Tecnologia (FCT)/Ministério da Ciência, Tecnologia e Inovação in the framework of the project "Institute for Research and Innovation in Health Sciences" (POCI-01-0145-FEDER-007274). Cátia DF Lopes acknowledges FCT for her PhD scholarship (SFRH/BD/77933/2011).

\section{Disclosure}

The authors report no conflicts of interest in this work.

\section{References}

1. Apfel SC. Is the therapeutic application of neurotrophic factors dead? Ann Neurol. 2002;51(1):8-11.

2. Hoyng SA, de Winter F, Tannemaat MR, Blits B, Malessy MJ, Verhaagen J. Gene therapy and peripheral nerve repair: a perspective. Front $\mathrm{Mol}$ Neurosci. 2015;8:32.

3. Nayerossadat N, Maedeh T, Ali PA. Viral and nonviral delivery systems for gene delivery. Adv Biomed Res. 2012;1:27.

4. Yellepeddi VK. Vectors for non-viral gene delivery - clinical and biomedical applications. Austin Therapeutics. 2015;2(1):1014.
5. Oliveira H, Fernandez R, Pires LR, et al. Targeted gene delivery into peripheral sensorial neurons mediated by self-assembled vectors composed of poly(ethylene imine) and tetanus toxin fragment c. J Control Release. 2010;143(3):350-358.

6. Evinger C, Erichsen JT. Transsynaptic retrograde transport of fragment $\mathrm{C}$ of tetanus toxin demonstrated by immunohistochemical localization. Brain Res. 1986;380(2):383-388.

7. Fishman PS, Carrigan DR. Retrograde transneuronal transfer of the C-fragment of tetanus toxin. Brain Res. 1987;406(1-2):275-279.

8. Carlton E, Teng Q, Federici T, Yang J, Riley J, Boulis NM. Fusion of the tetanus toxin $\mathrm{C}$ fragment binding domain and $\mathrm{Bcl}-\mathrm{xL}$ for protection of peripheral nerve neurons. Neurosurgery. 2008;63(6):1175-1182.

9. O'Leary VB, Ovsepian SV, Bodeker M, Dolly JO. Improved lentiviral transduction of ALS motoneurons in vivo via dual targeting. Mol Pharm. 2013;10(11):4195-4206.

10. Toivonen JM, Olivan S, Osta R. Tetanus toxin C-fragment: the courier and the cure? Toxins (Basel). 2010;2(11):2622-2644.

11. Sinha K, Box M, Lalli G, et al. Analysis of mutants of tetanus toxin Hc fragment: ganglioside binding, cell binding and retrograde axonal transport properties. Mol Microbiol. 2000;37(5):1041-1051.

12. Livak KJ, Schmittgen TD. Analysis of relative gene expression data using real-time quantitative PCR and the 2(-Delta Delta C(T)) Method. Methods. 2001;25(4):402-408.

13. Oliveira H, Rangl M, Ebner A, Mayer B, Hinterdorfer P, Pego AP. Molecular recognition force spectroscopy: a new tool to tailor targeted nanoparticles. Small. 2011;7(9):1236-1241.

14. Thakor D, Spigelman I, Tabata Y, Nishimura I. Subcutaneous peripheral injection of cationized gelatin/DNA polyplexes as a platform for non-viral gene transfer to sensory neurons. Mol Ther. 2007;15(12):2124-2131.

15. Grafstein B, Forman DS. Intracellular transport in neurons. Physiol Rev. 1980;60(4):1167-1283.

16. Mitchell K, Bates BD, Keller JM, et al. Ablation of rat TRPV1expressing Adelta/C-fibers with resiniferatoxin: analysis of withdrawal behaviors, recovery of function and molecular correlates. Mol Pain. 2010;6:94.

17. Suk JS, Suh J, Lai SK, Hanes J. Quantifying the intracellular transport of viral and nonviral gene vectors in primary neurons. Exp Biol Med (Maywood). 2007;232(3):461-469.

18. Wang S, Ma N, Gao SJ, Yu H, Leong KW. Transgene expression in the brain stem effected by intramuscular injection of polyethylenimine/ DNA complexes. Mol Ther. 2001;3(5 Pt 1):658-664.

19. Swett JE, Torigoe Y, Elie VR, Bourassa CM, Miller PG. Sensory neurons of the rat sciatic nerve. Exp Neurol. 1991;114(1):82-103.

20. Towne C, Pertin M, Beggah AT, Aebischer P, Decosterd I. Recombinant adeno-associated virus serotype 6 (rAAV2/6)-mediated gene transfer to nociceptive neurons through different routes of delivery. Mol Pain. 2009;5:52.

21. Aloe L, Rocco ML, Bianchi P, Manni L. Nerve growth factor: from the early discoveries to the potential clinical use. J Transl Med. 2012; 10:239.

22. Fink DJ, Wechuck J, Mata M, et al. Gene therapy for pain: results of a phase I clinical trial. Ann Neurol. 2011;70(2):207-212.
International Journal of Nanomedicine

\section{Publish your work in this journal}

The International Journal of Nanomedicine is an international, peerreviewed journal focusing on the application of nanotechnology in diagnostics, therapeutics, and drug delivery systems throughout the biomedical field. This journal is indexed on PubMed Central, MedLine, CAS, SciSearch ${ }^{\circledR}$, Current Contents ${ }^{\circledR} /$ Clinical Medicine,

\section{Dovepress}

Journal Citation Reports/Science Edition, EMBase, Scopus and the Elsevier Bibliographic databases. The manuscript management system is completely online and includes a very quick and fair peer-review system, which is all easy to use. Visit http://www.dovepress.com/ testimonials.php to read real quotes from published authors. 